\title{
The role of services and capital in footprint modelling
}

\author{
David Font Vivanco ${ }^{1}$
}

Received: 25 January 2019 / Accepted: 30 July 2019 / Published online: 8 November 2019

(C) The Author(s) 2019

\begin{abstract}
Purpose System incompleteness is an outstanding issue in footprint studies, causing systemic truncation errors and misestimation of results. This issue has many implications for analysts, from misleading conclusions in comparative assessments to hampering effective data exchange and comparability between models. A key element of system incompleteness is the treatment of services and capital, which are, respectively, often misrepresented in life cycle assessment (LCA, due to being largely missing in processbased databases) and input-output analysis (IOA, due to being exogenous to the intermediate uses). To gain insight into both the magnitude of such truncation errors and how to mitigate these, this paper analyses the impact of systematically including both services and capital in the system descriptions used in footprint analysis.

Methods Manufactured capital is endogenised into the input-output table (IOT) by using capital use information from growth and productivity accounts. Comprehensive service inputs are included in life cycle inventories (LCIs) by means of integrated hybrid LCA. For illustration purposes, the method is applied on two popular LCI and IOT databases-ecoinvent and EXIOBASE - and four common modelling applications of LCA and IOA: LCA- and IOA-based footprints, comparison between IOA and LCA footprints, and a case study using hybrid LCA.

Results and discussion The results suggest that the inclusion of both services and capital, either individually or in combination, leads to overall notable differences in footprint results, for example, median relative changes in carbon footprints of $41 \%$ and $12 \%$, respectively, for IOA- and LCA-based footprints. Such differences can have notable implications, such as redefining environmental 'hotspots' and reversing the results of comparative analyses. Results, however, vary greatly across applications, impact categories and industry/product types, and so specific implications will depend on the research question and scope of analysis. Overall, endogenising capital has a larger impact than including missing services.

Conclusions This exercise highlights two fundamental aspects for footprint modelling: the trade-offs between external and internal consistency and the facilitation of model integration. First, the proposed method increases system completeness of LCA (external consistency with the subject of study, namely economic systems) at the expense of internal inconsistencies stemming from ontological discrepancies between input-output and LCI systems (e.g. system completeness). This discrepancy can be mitigated by exploiting the potential of integrated hybrid LCA to create a highly interconnected hybrid system. Second, this approach shows how footprint models can complement each other towards more comprehensive and consistent descriptions of the socio-economic metabolism.
\end{abstract}

Keywords Ecoinvent $\cdot$ EXIOBASE $\cdot$ Footprint $\cdot$ LCI database $\cdot$ Life cycle inventories (LCI) Multi-regional input-output (MRIO) database

\section{Introduction}

Responsible editor: Yi Yang

Electronic supplementary material The online version of this article (https://doi.org/10.1007/s11367-019-01687-7) contains supplementary material, which is available to authorized users.

David Font Vivanco

david.font@lca-net.com

1 2.-0 LCA consultants, Rendsburggade 14, Room 4.315B, 9000 Aalborg, Denmark
The robustness of footprint ${ }^{1}$ results depends crucially on how complete is the system that is being described by a given model. System incompleteness leads to systemic truncation errors and misestimation of results, thus misleading conclusions about impact 'hotspots' and which products to promote

\footnotetext{
${ }^{1}$ In agreement with the majority of the literature, a footprint is here understood as the direct and indirect consequences of a given consumption (Minx et al. 2009).
} 
(Lenzen 2000; Suh et al. 2004). Furthermore, the subjectivity of system boundary selection can also lead to a lack of confidence in footprint studies (Suh et al. 2004). In practical terms, inconsistencies in boundary selection can lead to a wide range of challenges, from data storage issues (Myers et al. 2019) to hampering effective data exchange and comparability between models and disciplines (Creutzig et al. 2012). Popular footprint models, ${ }^{2}$ such as life cycle assessment (LCA) and (environmentally extended) input-output analysis (IOA), despite having the socio-economic metabolism (SEM) as their common subject of study, can however differ greatly in their description (Pauliuk et al. 2016). Several aspects involved in selecting system boundaries have been identified, including boundaries between the technological system and nature, geographical area, time horizon, capital stocks, connections between life-cycle systems (Tillman et al. 1994), services (Ward et al. 2018a), as well as the use and end-of-life stages (Joshi 1999).

In this paper, I focus on two key issues related to the description of production inputs: the implications of omitting both services and manufactured capital (from hereby referred to as just capital) in environmental footprint calculations. On the one hand, process-based life cycle inventory (LCI) databases used in LCA are known to systematically overlook a large share of services, namely processes that do not produce tangible commodities, such as business and technical services. This omission has been referred to as sideways truncation and can be due to "the assumed insignificance of their contribution to the final results, lack of awareness of their existence, and/or a lack of data" (Crawford et al. 2018, 1275). While services generally contribute modestly to direct resource use and emissions, their long and complex supply chains can entail significant environmental impacts (Nansai et al. 2009; Suh 2006; Ward et al. 2018a). For example, Ward et al. (2018a) estimated that omitting services in LCA-based carbon footprints would overlook $3 \%$ to $13 \%$ of total carbon emissions across sectors. Consequently, "omitting services and their supply chains from life-cycle databases and inventories is likely to cause significant systematic errors" (Pomponi and Lenzen 2018, 212).

On the other hand, input-output tables (IOTs) used for IOA do include a comprehensive range of services as intermediate inputs, but, unless modified from the original sources, do not provide detailed information on the capital inputs required by each industry, such as machinery and buildings used in production (Lenzen and Treloar 2004), which are largely included in LCI databases. Capital is instead reported exogenously in IOTs via two metrics: gross fixed capital formation (GFCF) and consumption of fixed capital (CFC). GFCF is reported as a final demand category

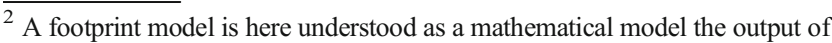
which is a footprint.
}

and is a measure of "the total value of a producer's acquisitions, less disposals, of fixed assets during the accounting period plus certain additions to the value of non-produced assets", while CFC is part of the value added and accounts for the "decline, during the course of the accounting period, in the current value of the stock of fixed assets owned and used by a producer as a result of physical deterioration, normal obsolescence or normal accidental damage" (EC et al. 2009). Both GFCF and CFC are aggregated into product or industry totals, and so it is not possible to keep track of supply and demand for capital goods or services. In other words, it is not possible to know which sector has provided de capital inputs in CFC or which sector or final use is making use of capital formed in GFCF. This 'exogenisation' of capital causes various limitations for footprint analysis, particularly with regard to adequately assessing the environmental impacts associated with (1) the intertemporal dynamics of capital use or the specific capital used each year (Chen et al. 2018), (2) capital formation (Södersten et al. 2018a) and (3) product footprints (Södersten et al. 2018b). For instance, according to Södersten et al. (2018b), allocating the monetary flows of manufactured capital to the products that use them as inputs increases national carbon footprints of final consumption by up to $57 \%$ for some regions, implying that most national and industry footprints may be greatly underestimated.

Even though both services and capital are fundamental for describing the SEM, they are often misrepresented in both LCA and IOA models, respectively, leading to systematic errors in footprint calculations. Specifically, key service inputs are partially or completely missing from LCI databases, such as financial and technical services, while capital use is generally not an intermediate input in IOTs. While the literature makes us aware of such systematic errors (Lenzen 2000; Majeau-Bettez et al. 2011; Pomponi and Lenzen 2018; Ward et al. 2018a), we know little about the extent to which they actually influence footprint results. To gain further insight into the role of services and capital in footprint modelling, this paper analyses the impact of including services and capital, respectively, in two of the most widely used databases: the LCI database ecoinvent 3.4 (Wernet et al. 2016) and the environmentally extended input-output database EXIOBASE 3.4 (Stadler et al. 2018). Improved insight into such impact can contribute to mitigate truncation errors, increase the robustness of footprint results, and help model integration and exchange. This paper is structured as follows: Section 2 describes the methods and data used to include services in ecoinvent and endogenise capital in EXIOBASE, Section 3 presents the results for four different modelling applications: IOA-based footprints, LCA-based footprints, comparison between IOA and LCA footprints, and a case study using hybrid LCA, Section 4 discusses the main results, and Section 5 concludes. 


\section{Methods and data}

To estimate the influence of including both capital and services in an IOT and an LCI, respectively, I used a rather pragmatic approach with the aim to minimise internal inconsistencies while covering the most industries/products in the databases. It is thus not my intention to obtain accurate results at the industry/ product level nor for the whole of any given database, but rather to obtain a first-order estimate of such influence. With this caveat in mind, in the following sections I describe the methods to endogenise capital in an IOT and include services in an LCI, using EXIOBASE and ecoinvent, respectively, as the reference databases. I have chosen these databases due to their quality, completeness, and representativeness of footprint modelling practice.

The IOT used in this study has been obtained from the multi-regional input-output (MRIO) database EXIOBASE 3.4 (Stadler et al. 2018) (https://www.exiobase.eu), corresponding to the year 2011 (the latest year available) and the monetary industry-by-industry configuration following the 'fixed product sales' model. This database contains all monetary transactions between 163 industries and final users across 49 regions (44 of the largest world economies and five 'rest-of-the-word' regions). It also contains a comprehensive coverage of environmental accounts (direct resource use and emissions in physical units). Note that EXIOBASE tables are also available as product-by-product (following the 'industry-technology' assumption), and such resolution would be closer to that of any LCI and so easier to match when combined. However, industry-by-industry is considered to have a higher statistical quality (Ahmad 2007). The LCI database corresponds to the 'allocation at the point of substitution' or APOS system model of the ecoinvent 3.4 database (Wernet et al. 2016), which includes almost 15,000 unit processes/products from 157 unique regions and more than 4000 environmental extensions. The APOS database is based mostly on partitioning by economic revenue and is the default system model by the data provider (Wernet et al. 2016). Note that the partitioning by economic revenue method in LCA is equivalent to both the 'fixed product sales' and 'industry technology' models in IOA (Majeau-Bettez et al. 2018), thus ensuring consistent treatment of co-production. Note that ecoinvent also provides the 'Allocation, cut-off by classification' system, which does not provide any credits to recycling or reuse of products. While this system is better aligned with the EXIOBASE database and would therefore improve the consistency of comparative analyses (see Section 2.3.3), the choice of the APOS system is here justified due to its better representativeness of LCA practice.

\subsection{Method to endogenise capital use in EXIOBASE}

In order to close the input-output system with regard to capital use, various approaches have been proposed to 'endogenise' capital within intermediate demand. The augmentation and the flow matrix methods stand out, yet the latter is theoretically more accurate for footprint analysis as it allows distinguishing between capital types (Lenzen and Treloar 2004). In short, the flow matrix method generates a capital flow matrix $K$ describing inter-industry capital flows, namely inputs and outputs of capital between suppliers and users of capital goods and services during a time period. Using standard input-output notation (Miller and Blair 2009), $K+Z$ then gives a modified inter-industry flow matrix $Z^{K}$, which includes both intermediates and capital as production inputs/ outputs, where $Z$ is the original inter-industry flow matrix.

To calculate $K$ for EXIOBASE, I largely followed the approach described by Södersten et al. (2018a, b), which use growth and productivity accounts (EU KLEMS and World KLEMS (Jäger 2016)) to endogenise CFC into the interindustry matrices of a MRIO system. The authors argue that endogenising CFC is more suitable for footprint-type calculations since CFC measures the capital currently used by industries, rather than investments in new capital, represented by GFCF. Endogenising GFCF instead would therefore be problematic, for example, because spikes in production (e.g. after a catastrophic event such as a flood) will be attributed to past production and because capital formation is largely but not exclusively used by productive activities (EC et al. 2014). Consequently, emissions embodied in GFCF are significantly larger than those embodied in CFC and so using the former would lead to overestimate consumption-based footprints (Chen et al. 2018). For specific details on the assumptions, equations, limitations, etc., I refer to Södersten et al. (2018b). In short, this approach follows four general steps:

1. KLEMS-based national capital input matrices (as industry-by-asset (40-by-11, see below) and for countries where such data is available) are converted to EXIOBASE classification (as industry-by-industry (163by-163)) using distribution keys based on GFCF and CFC from EXIOBASE. Specifically, KLEMS industries are disaggregated by means of a 40-by-163 concordance matrix, where GFCF is used as a distribution key. Moreover, KLEMS capital assets are disaggregated by means of a 163-by-11 concordance matrix, where CFC is used as a distribution key.

2. An EXIOBASE-based generic distribution matrix is built based on an average of the available capital input matrices. Such generic matrix is used to represent capital inputs in those regions not covered in existing growth and productivity accounts, so that all 49 regions in EXIOBASE have a capital input matrix. 
3. Each of the 49 EXIOBASE-based national capital input matrices are distributed across regions using the origin structure of GFCF. This step generates 49 163-by-163 matrices, of which one is the domestic capital input matrix (capital formed and used domestically) and the rest are imported capital input matrices (capital formed elsewhere but used domestically).

4. The resulting 7987-by-7987 EXIOBASE-based multi-regional capital input matrix is then reconciled to match region-specific CFC row and column totals from EXIOBASE. This step is performed using a scaling algorithm, specifically the popular RAS algorithm, which is often used to balance input-output tables (Miller and Blair 2009).

I apply the same approach with the exception that I have only used the EU KLEMS database (http://www.euklems. net/) for simplicity. This means that the generic distribution matrix used to construct the rest of national capital input matrices is based solely on the regions in EU KLEMS. EU KLEMS provides capital input data in national currencies for the EU27 countries (except Belgium) plus the USA. Specifically, the database contains 11 capital assets (computing equipment, communications equipment, computer software and databases, transport equipment, other machinery and equipment, total non-residential investment, residential structures, cultivated assets, research and development, and other intellectual property assets) used by 40 industry types for various years.

\subsection{Method to systematically include service inputs in ecoinvent}

To include service inputs in ecoinvent 3.4, I first identify those services that are largely missing from the database. Most LCI databases, including ecoinvent, include some types of services, mostly related to transport and waste management services and, to a lesser degree, other such as professional, scientific and technical services (Majeau-Bettez et al. 2011). To identify missing services, I use the unique International Standard Industrial Classification of All Economic Activities (ISIC) code assigned to each unit process or activity by ecoinvent (https://www.ecoinvent.org). Leaving out transport and waste management services due to their overall good representation, I define missing services as those pertaining to ISIC-based sections G (Wholesale and retail trade; repair of motor vehicles and motorcycles), I (Accommodation and food service activities), $\mathrm{J}$ (Information and communication), $\mathrm{K}$ (Financial and insurance activities), L (Real estate activities), M (Professional, scientific and technical activities), N (Administrative and support service activities), O (Public administration and defence; compulsory social security), $\mathrm{P}$ (Education), Q (Human health and social work activities), R
(Arts, entertainment and recreation), S (Other service activities), $\mathrm{T}$ (Activities of households as employers; undifferentiated goods- and services-producing activities of households for own use), and $\mathrm{U}$ (Activities of extraterritorial organisations and bodies). Then, to avoid double-counting, for the relatively few unit processes that pertain to these sections (about 3\% from the total), I set all inputs from these service activities to zero.

Once the missing services have been identified, I systematically include these into the original LCI by means of the integrated hybrid LCA approach (Crawford et al. 2018). In short, this approach integrates both a linked LCI in matrix form and an IOT into a single matrix and interconnects both via so-called cut-off matrices (see Section 2.3 for further details). The cut-off matrices represent industry inputs into processes (upstream cut-off matrix) and product inputs into industries (downstream cut-off matrix). The upstream cut-off matrix can thus be used to incorporate the selected services to each process, as each cell in this matrix represents how many monetary units of a given industry are required to produce one unit of a given process' output. The downstream cut-off matrix is not be used in this approach and is equal to a zero matrix (see Section 2.3).

While it is possible to build individualised service input structures for all processes, this would be a highly resourceintensive task. For this reason, I used a rather pragmatic approach that focuses on simplicity and internal consistency (the same assumptions hold true across processes) at the expense of accuracy. Specifically, I rely on two basic assumptions. First, the service input structure of each process must be as close as possible to that of one or more given representative industries. For example, if the industry 'petroleum refinery' requires 0.1 monetary units of 'research and development' inputs for every monetary unit of output, all the corresponding processes, such as 'coking', also require the same proportion of service input to produce their reference products. Second, monetary balances must be respected, namely the price of all inputs (service and non-service) of a given process to produce a reference product must not be higher than the price of the reference product. Following these assumptions, an upstream cut-off matrix indicating the service inputs into processes $\left(C_{u}^{s}\right.$ ), or the euros of service inputs required to produce a physical unit of product, can be derived as:

$C_{u}^{s}=\hat{f A_{I O} t \hat{p} \hat{b}}$

Where $A$ is a $k \times k$ matrix of technical coefficients (in million euros by million euros) indicating the inter-industry inputs required to supply one unit of output, $k$ being the number of industries, $f$ is a dimensionless $k \times 1$ vector which flags service and non-service industries with ones and zeroes (see Electronic Supplementary Material), respectively, with the hat indicating diagonalisation, $t$ is a dimensionless $k \times m$ 
concordance matrix between industries and unit processes where each unit process is assigned one or more industries, $p$ is a $m \times 1$ vector containing the prices for all processes' products (in million euros per physical unit), with $m$ being the number of processes, and $b$ is a dimensionless $m \times 1 \mathrm{scal}-$ ing vector with either ones (no scaling needed) or values between zero and one (downscaling needed to ensure economic balance).

To build $t$, each unit process is assigned at least one industry type according to its ISIC code. Additionally, each geography in ecoinvent is also assigned one or more geographies from EXIOBASE. Accordingly, a one-to-one match between a unit process and an industry (considering industry type and geography) corresponds to a value of one in the concordance matrix, whereas if one unit process is assigned more than one industry, a weighting is applied according to total output so that each column total equals to one. In the special case of the ecoinvent geography 'rest-of-world', which corresponds to a residual difference between a global dataset and the nonglobal datasets for any given activity (Weidema et al. 2013), the corresponding EXIOBASE geographies are assigned accordingly. Full industry type and geographical concordances can be found in the Electronic Supplementary Material.

To build $p$, price data for each process' reference product is obtained from ecoinvent (Wernet et al. 2016). From all processes in ecoinvent 3.4, I focus exclusively on transforming processes, leaving out market processes, namely processes that mix similar outputs from transforming processes and supply consumption mixes (Weidema et al. 2013). In ecoinvent 3.4 , market processes are generally placed in between any two transforming processes and originally include transport and wholesale and/or retailer activities (e.g. re-packaging and advertising) (Weidema et al. 2013). Because markets do not supply products but consumption mixes, including additional services to both transforming and market processes would generate double-counting of service inputs as sectors from the IOT do not distinguish between transforming and market sectors. Accordingly, the price of market processes is set to zero and so these do not contain additional service inputs aside from the original transport services. Most reference products from transforming processes have a price property as basic price in euros for 2005. A necessary step is thus to consider inflation rates to obtain prices for 2011 in order to match the IOT data. Specifically, I used the accumulated inflation rate of change for the Euro area for the period 2005-2011 (Eurostat 2018). Considering only those transforming activities with price information gives price data for 9050 activities or $61 \%$ from the total. To ensure that economic balances are maintained, I built a scaling vector $b$. Specifically, the price of all (non-service) inputs is calculated by assuming that the price of each input equals that of the corresponding reference product (Weidema et al. 2013). In case that the economic value of all inputs (service and non-service inputs) is higher than the price of the reference product, a scaling factor between zero and one is calculated to ensure that the value of inputs equals the value of outputs, and otherwise the factor corresponds to one. Note that the scaling vector does not consider additional inputs such as labour costs and trade margins, which are missing from the database.

\subsection{Footprint calculations}

To estimate the implications of both including services and endogenising capital, I carried out four types of footprint calculations: IOA-based footprints for each industry output to final demand (see Section 2.3.1), LCA-based footprints for each unit process' reference product (see Section 2.3.2), a comparative analysis between LCA and IOA-based footprints (see Section 2.3.3), and a case study of rebound effects from electric cars using hybrid LCA (see Section 2.3.4). All calculations were based on the integrated hybrid LCA approach (Crawford et al. 2018), where services can be included via the upstream cut-off matrix and capital can be endogenised in the input-output system (see Fig. 1 for an overview). Note that both LCA and IOA-based footprints can be calculated with the integrated hybrid LCA approach by respectively shocking the system through either the processes or industries' final demand. This approach therefore understands the integrated hybrid LCA as a mathematical framework (Crawford et al. 2018) rather than a two-way interconnected and balanced system (Suh 2004). Footprint results for a given environmental impact $e$ (e.g. climate change as $\mathrm{CO}_{2}$ equivalents) associated with any given final demand were calculated using the standard demand-pull Leontief model (Miller and Blair 2009):

$$
\begin{aligned}
& \text { footprint }_{e}=i_{e}^{T} x=i_{e}^{T}(L y)=\left(c_{i} s_{i}\right)^{T}\left(H^{-1} y\right) \\
& H=\left(\begin{array}{cc}
I_{L C I}-A_{L C I} & -C_{d} \\
-\left(C_{u} \mid C_{u}^{S}\right) & I_{I O}-\left(A_{I O} \mid \mathrm{A}^{K}{ }_{I O}\right)
\end{array}\right) \\
& s=\left(\begin{array}{c}
s_{L C I} \\
s_{I O}
\end{array}\right) ; c=\left(\begin{array}{c}
c_{L C I} \\
c_{I O}
\end{array}\right)
\end{aligned}
$$

Using standard input-output notation (Miller and Blair 2009), $y$ is a given $n \times 1$ final demand vector, being $n$ the combined number of unit processes $(m)$ and industries $(k)$, $A_{L C I}$ is an $m \times m$ matrix of technical coefficients indicating the inter-process inputs required to supply one unit of a product, $I_{L C I}$ is an $m \times m$ identity matrix, $A_{I O}$ is a $k \times k$ matrix of technical coefficients indicating the inter-industry inputs required to supply one unit of output (with the superscript $k$ indicating that capital is endogenous and otherwise assumed to be exogenous and the vertical line indicating alternation), $I_{I O}$ is a $k \times k$ identity matrix, $C_{s}$ is a $k \times m$ upstream cut-off matrix indicating the industry inputs into processes (with the superscript $s$ indicating that it includes service inputs and otherwise assumed to be a zero matrix), $C_{d}$ is an $m \times k$ 
Fig. 1 Overview of the proposed integrated hybrid life cycle assessment system and the proposed inclusion of services and capital, respectively, into the life cycle inventory and inputoutput systems

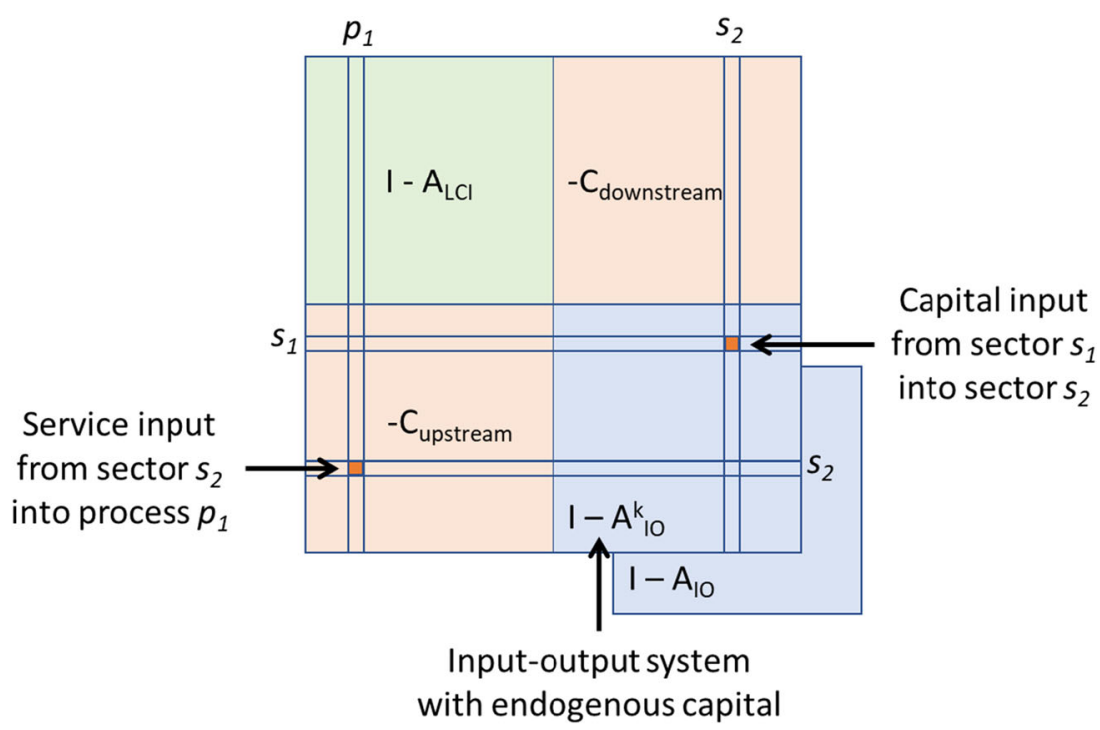

downstream cut-off matrix indicating the product inputs into industries (assumed here to be a zero matrix), $s_{L C I}$ is an $m \times 1$ vector of environmental stressors per unit of product, $s_{I O}$ is a $k \times 1$ vector of environmental stressors per unit of output, $c_{L C I}$ and $c_{I O}$ are $m \times 1$ and $k \times 1$ vectors, respectively, of impact characterisation factors (impact per stressor), $L$ is the Leontief inverse containing the multipliers for the direct plus indirect inter-industry/process inputs required to satisfy one unit of $y$ and $i$ is an $n \times 1$ vector of impact coefficients (impact per unit of output), with the superscript $T$ indicating transposition.

Both $A_{L C I}$ and $s_{L C I}$ correspond to the APOS system model of the ecoinvent 3.4 database, parsed into calculation-ready matrices from the original Ecospold files with a dedicated Rbased script (https://github.com/dfontv/Rtools/blob/master/ Spold_to_matrix_v1.1_GH.R). Both $A_{I O}$ and $s_{I O}$ correspond to the 2011 monetary industry-by-industry environmentally extended input-output table from the EXIOBASE 3.4 database. $c_{L C I}$ has been built using life-cycle impact characterisation factors by the International Reference Life Cycle Data System (ILCD) (http://eplca.jrc.ec.europa.eu/LCDN/ developerILCDDataFormat.xhtml) and provided by ecoinvent. $c_{I O}$ has been built using the characterisation factors for ILCD impact categories provided by Huysman et al. (2016). Among all impact categories in the ILCD framework, I selected, based on the availability of both stressor and characterisation factor data (Huysman et al. 2016), the following midpoint impacts: climate change (CC), particulate matter (PM), photochemical ozone formation (POF) and acidification (A).

\subsubsection{IOA-based footprints}

To calculate the footprint of individual industry outputs, I applied Eq. 2 using a diagonalised $n \times 1$ final demand vector where all $k$ industries have a value of 1 (using the actual final demand would yield the same results as I am interested in the relative changes) and all $m$ processes have zeroes. When constructing the $H$ matrix, it is possible to use the reference IOT (Reference) as well as the IOT with endogenised capital (Capital).

\subsubsection{LCA-based footprints}

To calculate the footprint of individual products, I applied Eq. 2 using a diagonalised $n \times 1$ final demand vector where all $m$ processes have a value of 1 and all $k$ industries have zeroes. When constructing the $H$ matrix, it is possible to use the reference LCI (Reference), include only services (Services), and include both services and capital (Services + capital).

\subsubsection{Comparative analysis}

Footprint analyses sometimes compare the results of both LCA and IOA in order to account for differences in technology detail, system completeness, etc. (Huysman et al. 2016; Teh et al. 2017). In a similar vein, I tested the impact of including both services and capital in comparative analyses with a simple exercise. Specifically, I compared unique combinations of ISIC class and geography in ecoinvent with their industry counterparts from EXIOBASE. To match processes from ecoinvent with industries from EXIOBASE, I used the previously described industry type and geographical concordances. Such comparison can only be carried out for those processes with price data (see Section 2.2), with which is possible to harmonise the units of both systems. Additionally, ecoinvent provides production volume data for most unit processes with price data, and so it is possible to weight the contribution of each individual process in each class-geography combination by total output (price times production volume). For example, 16 unit processes pertaining to the region 'Europe' correspond to the ISIC class '0220: Logging', with the corresponding EXIOBASE industries being of the type 'Forestry, logging 
and related service activities (02)' in 31 different regions. To calculate the LCA-based footprint in this example, I built a final demand vector $y^{L C I}$ where the 16 processes deliver 1 million euros (in 2011 euros as described in Section 2.2) weighted by their total output. To calculate the corresponding IOA-based footprint, I built a final demand vector $y^{I O}$ where the 31 industries also deliver 1 million euros weighted by their total output.
After applying Eq. 2, the resulting footprints from both $y^{L C I}$ and $y^{I O}$ can be compared in their reference configurations (Reference), including only services (Services), including only capital (Capital), or including both services and capital (Services $+\mathrm{capital}$ ). The results of the comparison are expressed as a relative change of the difference between individual footprints:

relative change $=\frac{(L C A \text { reference result }-I O A \text { reference result })-(L C A \text { result }-I O A \text { result })}{L C A \text { reference result }-I O A \text { reference result }}$

\subsubsection{Hybrid LCA case study on rebound effects from electric cars}

The use of hybrid LCA for footprint analysis, where both LCI and a IO systems are combined in a variety of ways - tiered, path exchange, matrix augmentation and integrated-has gained momentum in the last 20 years due to the possibility to mitigate inherent limitations of both LCA and IOA (Crawford et al. 2018). To test the implications of including both services and capital in a hybrid LCA application, I selected a simplified case study on environmental rebound effects associated with electric cars in the UK, similar to Font Vivanco et al. (2014, 2016). Specifically, the total cost of ownership (TCO) of electric cars is, on average, lower than their petrol counterparts (Palmer et al. 2018), which leads to economic savings and additional consumption (for both additional car driving and other consumption). Under the assumption of a savings closure (Francois and McDonald 1996), namely that all savings are eventually allocated to additional consumption, the embedded environmental impacts of such additional consumption lead then, when attributed to the life cycle of the electric car, to offset part of the original environmental savings. In this context, the cars' footprint is better calculated with technology-detailed inventories in LCA, while the footprint of the additional consumption, which is distributed along many and broad consumption categories, is better calculated via IOA because complete household expenditures are readily available in IOTs (Font Vivanco and van der Voet 2014). The proposed case study thus focuses on comparing the environmental footprint of a petrol car with that of an electric one plus induced additional consumption.

Following a recent and comprehensive study by Palmer et al. (2018), the TCO per kilometre of electric and petrol cars in the UK was 0.35 and 0.39 pounds in 2015, respectively. Applying official exchange and inflation rates (ECB 2018; Eurostat 2018), this gives economic savings per kilometre of about 0.06 in 2011 euros. That is, to the life-cycle environmental impacts associated with the electric car, we must now add the rebound effect or the impacts associated with
0.06 euros of marginal consumption. Note that this simplified approach ignores intertemporal effects, such as inflation and delayed expenditure from savings. The life-cycle environmental impacts associated with both an electric and a petrol car are obtained, respectively, from the unit processes 'transport, passenger car, electric' from the global geography (in the absence of a European process) and 'transport, passenger car, medium size, petrol, EURO 5' from the European geography, both delivering one passenger kilometre (pkm). It is assumed that a medium-sized petrol EURO 5 technology offers comparable features to an average electric car in terms of size, emissions, and technology level. For simplicity, the distribution of monetary savings is applied according to the shares on the total expenditure by households (Freire-González 2011). To calculate the corresponding footprints, and following the integrated hybrid LCA method proposed here (see Eq. 2), I built two final demand vectors: $y^{\text {petrol }}$ containing $1 \mathrm{pkm}$ of petrol car, and $y^{\text {electric }}$ containing $1 \mathrm{pkm}$ of electric car plus 0.06 euros distributed according to expenditure patterns of UK households as reported in EXIOBASE. The two footprints can be calculated in their reference configurations (Reference), including only services (Services), including only capital (Capital), or including both services and capital (Services + capital). Following convention, the rebound effect can be calculated as the percentage of environmental savings that are offset or 'taken back' (Font Vivanco et al. 2014), as

rebound effect $=\left(\frac{\text { potential savings }- \text { actual savings }}{\mid \text { potential savings } \mid}\right) \times 100$

\section{Results}

\subsection{IOA-based footprints}

Endogenising capital, namely reallocating impacts from the consumption of fixed capital (CFC) to final demand, causes overall notable increases in the IOA-based footprints with respect to the reference results (see Fig. 2). For all individual 


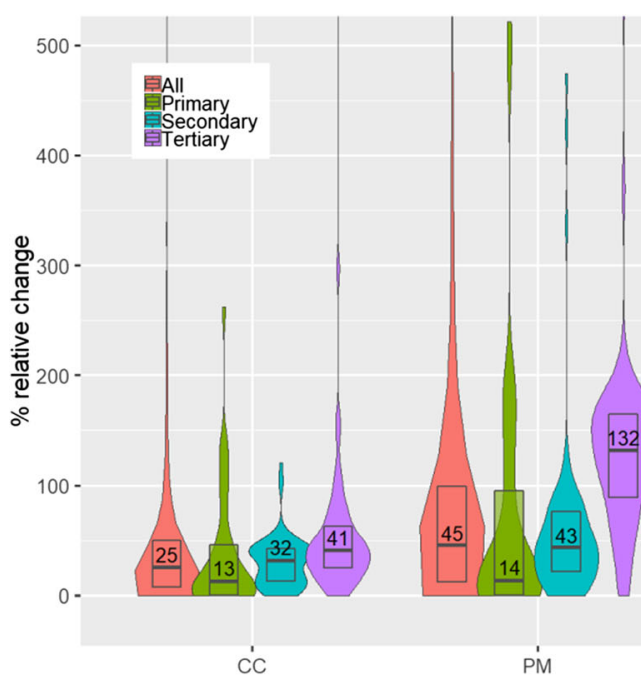

Fig. 2 Violin plot of the relative changes (as a percentage change of the difference between the results with and without capital endogenisation with respect to the latter) of individual footprints based on input-output analysis for various midpoint impact categories caused by endogenising capital. Results are classified in four series: results for all industry outputs (All) as well as for outputs from primary, secondary and tertiary industries (see supporting information for full correspondence). The plots show the

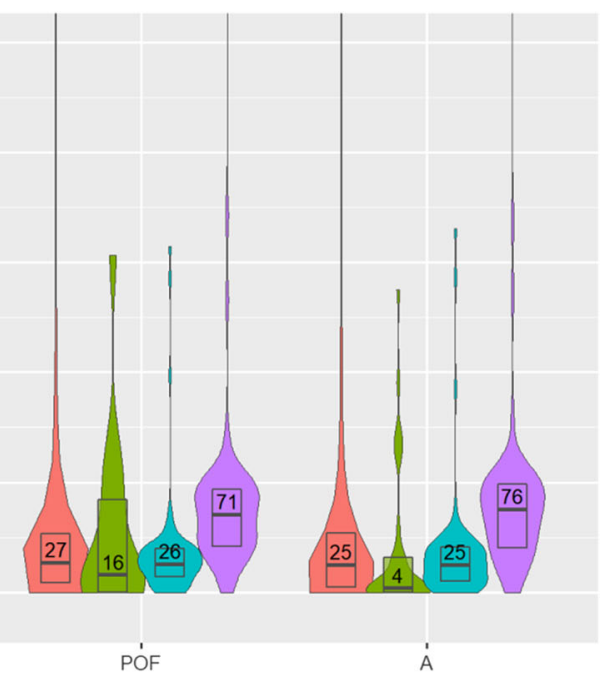

median (indicated by the thick horizontal band and the numerical value), the first through the third interquartile range or middle $50 \%$ (the open box), and the estimator of the density (the thin vertical curves). CC, climate change (in $\mathrm{kg} \mathrm{CO}_{2}$-eq); $\mathrm{PM}$, particulate matter (in $\mathrm{kg} \mathrm{PM} 2.5$ eq); $\mathrm{POF}$, photochemical ozone formation (in $\mathrm{kg} \mathrm{C}_{2} \mathrm{H}_{4}$-eq); A, acidification (in accumulated exceedance)

capital). Across modelling configurations (Services or Services + capital), the inclusion of capital would increase additional impacts from the IO system by about $30 \%$ to $70 \%$. This is consistent with the fact that endogenising capital has a larger effect in tertiary industries (where services belong to), often more than doubling environmental impacts with respect to Reference results (see Fig. 2). No notable differences are observed across impacts. Note that negative relative changes arise when waste treatment activities, which can yield credits (negative emissions) due to avoided primary production, include service inputs that reduce such credits. Across activity types, represented by ISIC classes, and for climate change (in $\mathrm{kg} \mathrm{CO}_{2}$-eq) as an example, the inclusion of both services and capital has a larger impact on activities pertaining to divisions related to agriculture (0103), manufacturing (10-33) and construction (41-43) (see Fig. 5). Specifically, five classes show median increases higher than $100 \%$, meaning that the individual footprints of unit processes pertaining to these classes would likely double when including both services and capital. Generally, such large differences are explained by either a low reference LCA-based footprint (e.g. from incomplete inventories), high additional impacts from services according to the IOA-based footprint or a combination of both. Taking the class describing the highest median relative change, 0230: Gathering of non-wood forest products, for illustration purposes, service inputs only represent about $7 \%$ to $15 \%$ from the output price, yet these contribute to notable additional climate change impacts mostly via retail and wholesale trade activities. tion formation-Services) to $16 \%$ (acidification-Services + 


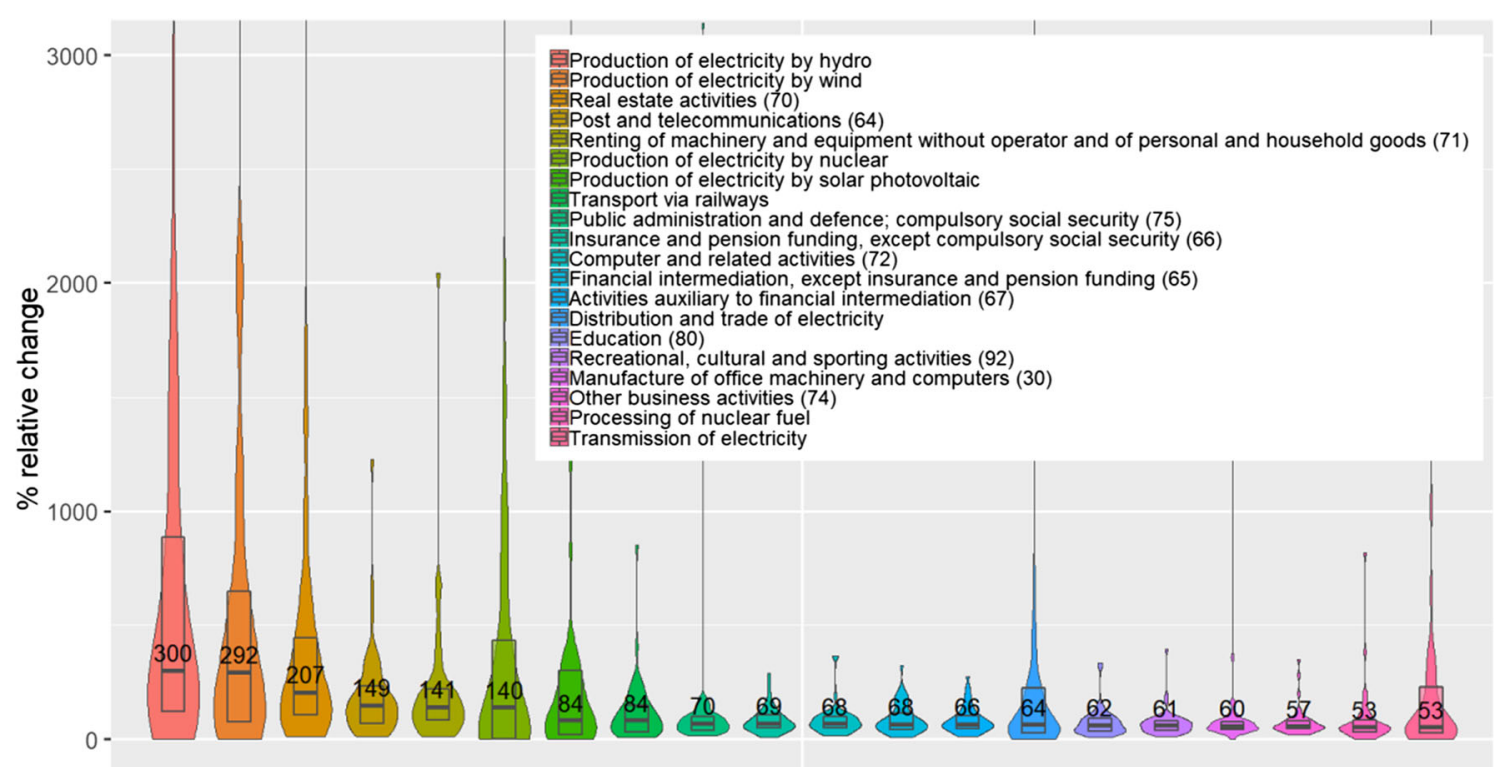

Fig. 3 Violin plot of the relative changes (as a percentage change of the difference between the results with and without capital endogenisation with respect to the latter) of individual footprints based on input-output analysis for climate change caused by endogenising capital. Results are presented by industry (163) and for the top 20 in terms of median value in

\subsection{Comparison between IOA and LCA-based footprints}

Comparative analyses using both IOA and LCA are also highly sensitive to the inclusion of both services and capital (see Fig. 6). Across both impacts and modelling configurations, the median of the relative change of the differences for decreasing order. The plots show the median (indicated by the thick horizontal band and the numerical value), the first through the third interquartile range or middle $50 \%$ (the open box), and the estimator of the density (the thin vertical curves)

a given modelling configuration with respect to the differences in the Reference results (see Eq. 3) range from $-38 \%$ (for particulate matter impacts and Capital configuration) to a $4 \%$ difference (for climate change, particulate matter, and acidification impacts and Services configuration). Note that, according to Eq. 3, a positive sign means that the change increases a given LCA footprint relatively more than its

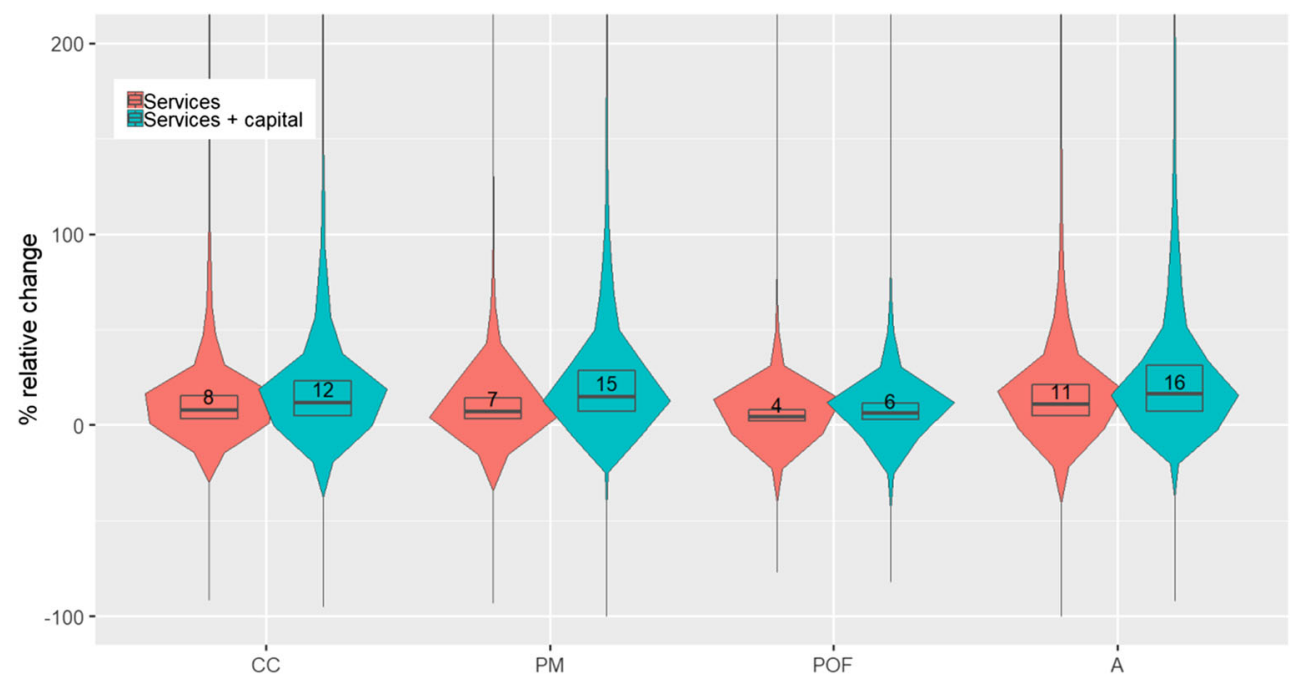

Fig. 4 Violin plot of the relative changes (as a percentage change of the difference between the results with and without including services with respect to the latter) of individual footprints based on life cycle assessment for various midpoint impact categories caused by including only services as well as both including services and endogenising capital (Services + capital). The plots show the median (indicated by the thick

horizontal band and the numerical value), the first through the third interquartile range or middle $50 \%$ (the open box), and the estimator of the density (the thin vertical curves). $\mathrm{CC}$, climate change (in $\mathrm{kg} \mathrm{CO}_{2}$-eq); PM, particulate matter (in kg PM2.5-eq); POF, photochemical ozone formation (in $\mathrm{kg} \mathrm{C}_{2} \mathrm{H}_{4}$-eq); $\mathrm{A}$, acidification (in accumulated exceedance) 


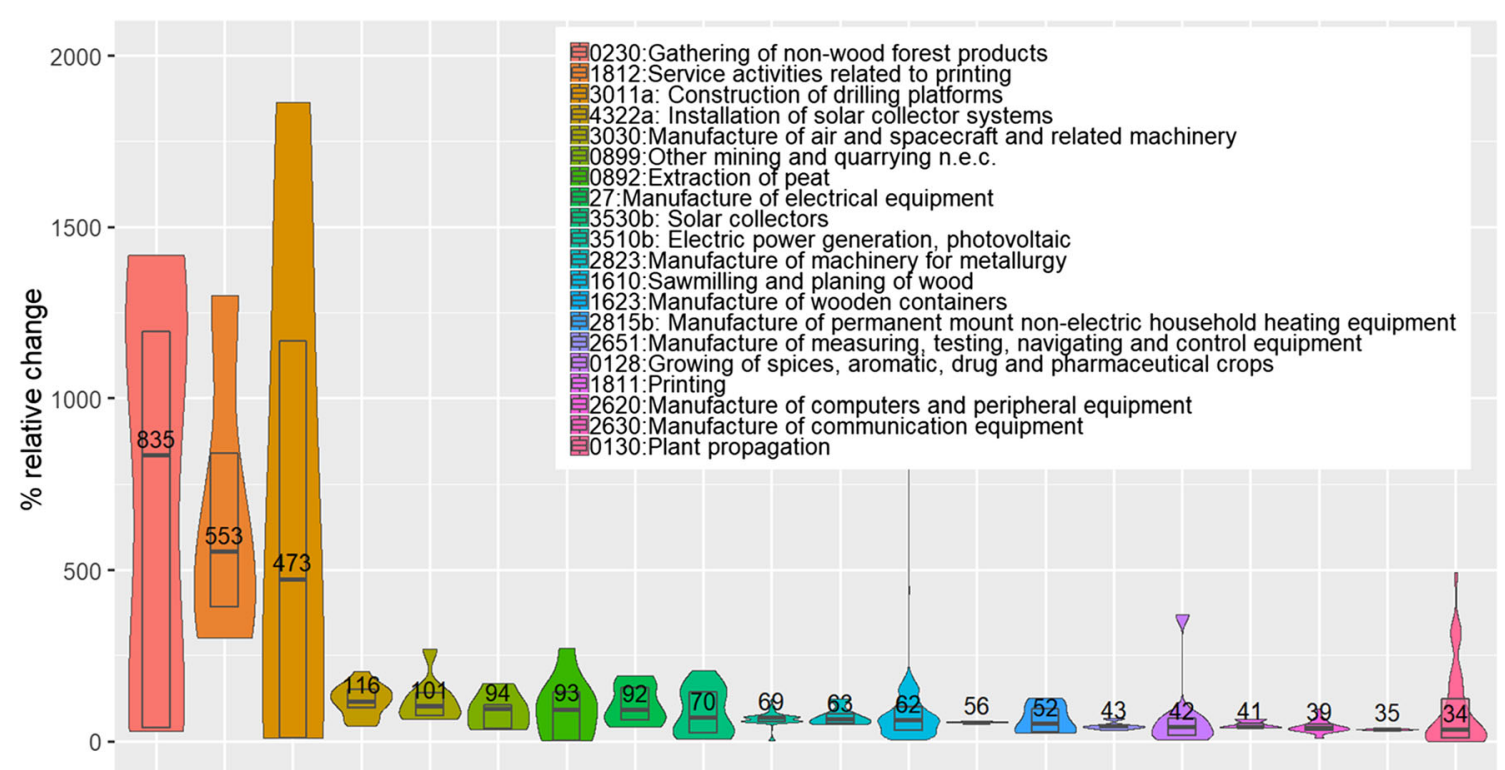

Fig. 5 Violin plot of the relative changes (as a percentage change of the difference between the results with and without including services with respect to the latter) of individual footprints based on life cycle assessment for climate change caused by both including services and endogenising capital. Results are presented by ISIC class (794) and for the top 20 in terms of median value in decreasing order. The plots show the median (indicated by the thick horizontal band and the numerical value), the first through the third interquartile range or middle $50 \%$ (the open box), and the estimator of the density (the thin vertical curves) corresponding IOA-based footprint, and vice versa. By modelling configuration, the inclusion of services causes a median relative change of about $4 \%$ for all impacts, while the inclusion of capital causes a median relative change ranging from $-38 \%$ (particulate matter) to $-15 \%$ (photochemical ozone formation). Moreover, the configuration Services + capital causes a relative change ranging from $-25 \%$ (particulate matter) to $-9 \%$ (photochemical ozone formation and acidification), which means that including both services and capital in a comparative analysis does, in general terms, increase relatively more the value of IOA, rather than LCAbased, footprints.

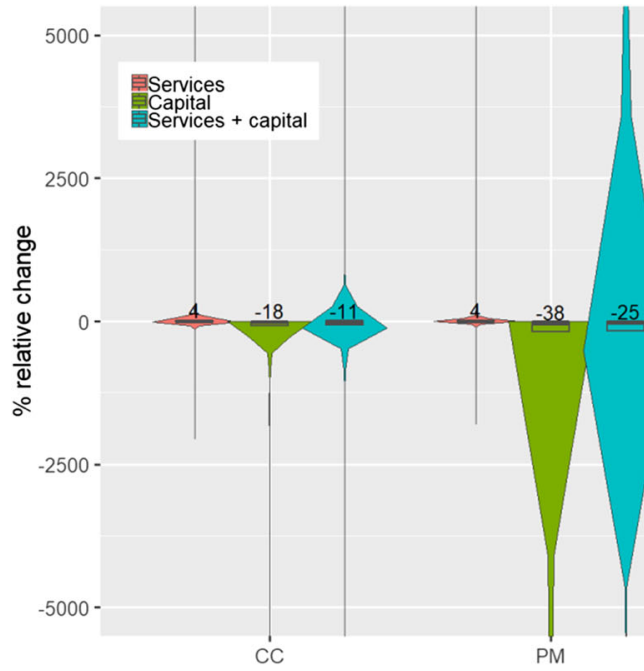

Fig. 6 Violin plot of the relative changes of differences between individual footprints (as life cycle assessment (LCA) result-input-output analysis (IOA) result for a given modelling configuration) with respect to differences in reference results (as reference LCA result- reference IOA result) for various midpoint impact categories caused by including only services, only endogenising capital, and both including services and endogenising capital (Services + capital). The plots show the

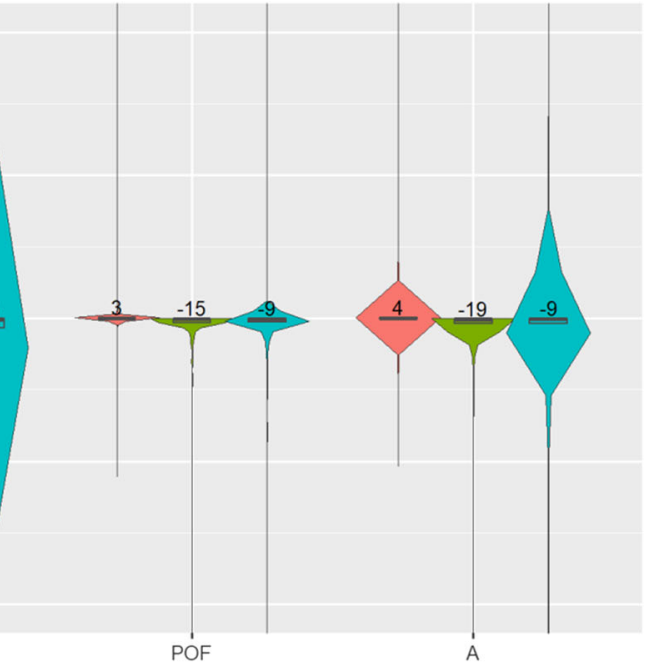

median (indicated by the thick horizontal band and the numerical value), the first through the third interquartile range or middle $50 \%$ (the open box), and the estimator of the density (the thin vertical curves). CC, climate change (in $\mathrm{kg} \mathrm{CO}_{2}$-eq); $\mathrm{PM}$, particulate matter (in $\mathrm{kg}$ PM2.5eq); POF, photochemical ozone formation (in $\mathrm{kg} \mathrm{C}_{2} \mathrm{H}_{4}$-eq); A, acidification (in accumulated exceedance) 


\subsection{Hybrid LCA case study}

The inclusion of both services and capital also has a relevant impact when calculating rebound effects from electric cars through hybrid LCA (see Fig. 7 and the Electronic Supplementary Material for full results). With respect to reference results, including both services and capital increases the rebound effect (calculated as in Eq. 4) in all impacts except for acidification (more environmental savings are 'taken back'). For example, the rebound effect in terms of climate change impacts increases by $55 \%$. Moreover, for photochemical oxidation, the rebound effect shifts from $64 \%$ (reference) to $1400 \%$ (services + capital), meaning that omitting services and capital in the hybrid system would overlook a potentially relevant backfire effect or the complete offsetting of environmental savings (Saunders 2000). Across modelling configurations, and consistent with previous results (see Section 3.3), including capital in the IO system has generally a larger impact than including services in the LCI system. By technology (petrol vs. electric car), including services has a larger impact on the electric car due to higher service requirements (e.g. research and development), while endogenising capital does not have a clear comparative effect (see Electronic Supplementary Material).

\section{Discussion}

The results suggest that the inclusion of both services and capital, either individually or in combination, in the system descriptions of footprint models may lead to overall notable differences in footprint results. The results further show that such differences can lead to practical implications for analysts, such as redefining the environmental 'hotspots' of economic systems and reversing the results of comparative analyses. Such differences, however, vary greatly across applications-IOA-based footprints, LCA- based footprints, comparative analysis and hybrid LCA-impact categories and industry/product types. Overall, endogenising capital in the IO system has a larger impact than including services in the LCI system for the studied systems.

The impact of endogenising capital in IOA-based footprints in this study appears to be more or less consistent with the literature. For instance, Södersten et al. (2018b), which applied a method largely followed in this study, calculated the effects of endogenising CFC in terms of changes in national carbon footprints and found that differences across regions range from $7 \%$ to $48 \%$. For GFCF, its carbon footprint has been estimated as $30 \%$ from the total (Södersten et al. 2018a). Moreover, Crawford (2008) estimated the impact of capital inputs in the embodied energy of buildings to be in the range of $8 \%$ to $22 \%$. These magnitudes are similar to the $25 \%$ median relative change found in this article. Regarding the inclusion of services in LCA-based footprints, Ward et al. (2018a) estimated a truncation error or relative change ranging from $3 \%$ to $13 \%$ across sectors for carbon footprints. The results presented here suggest a similar level of truncation, with a median relative change for climate change of $12 \%$ and $8 \%$ with and without endogenising capital. Regarding the calculation of rebound effects from electric cars through hybrid LCA, including both services and capital suggests a higher size than previous estimates, i.e. $56 \%$ for climate change compared with $44 \%$ with optimistic future subsidies (Font Vivanco et al. 2016).

This study contributes to the understanding of the impact of misrepresenting services and capital in footprint modelling by offering a comprehensive analysis applied to four popular footprinting applications: IOA-based footprints, LCA-based footprints, comparative analysis and hybrid LCA. Previous studies have focused on rather specific cases, such as the role of capital use in national carbon footprints (Södersten et al. $2018 \mathrm{~b}$ ), or the role of services in carbon emissions from Japan's households (Nansai et al. 2009). Previous studies have also estimated such truncation errors with insufficient scope
Fig. 7 Rebound effect (as a percentage of environmental savings that are 'taken back') associated with electric cars in the United Kingdom for various midpoint impact categories and modelling configurations: reference, including only services, only endogenising capital, and both including services and endogenising capital (Services + capital). CC, climate change (in $\mathrm{kg} \mathrm{CO}_{2}$-eq); $\mathrm{PM}$, particulate matter (in kg PM2.5eq); POF, photochemical ozone formation (in $\mathrm{kg} \mathrm{C}_{2} \mathrm{H}_{4}$-eq); $\mathrm{A}$, acidification (in accumulated exceedance)

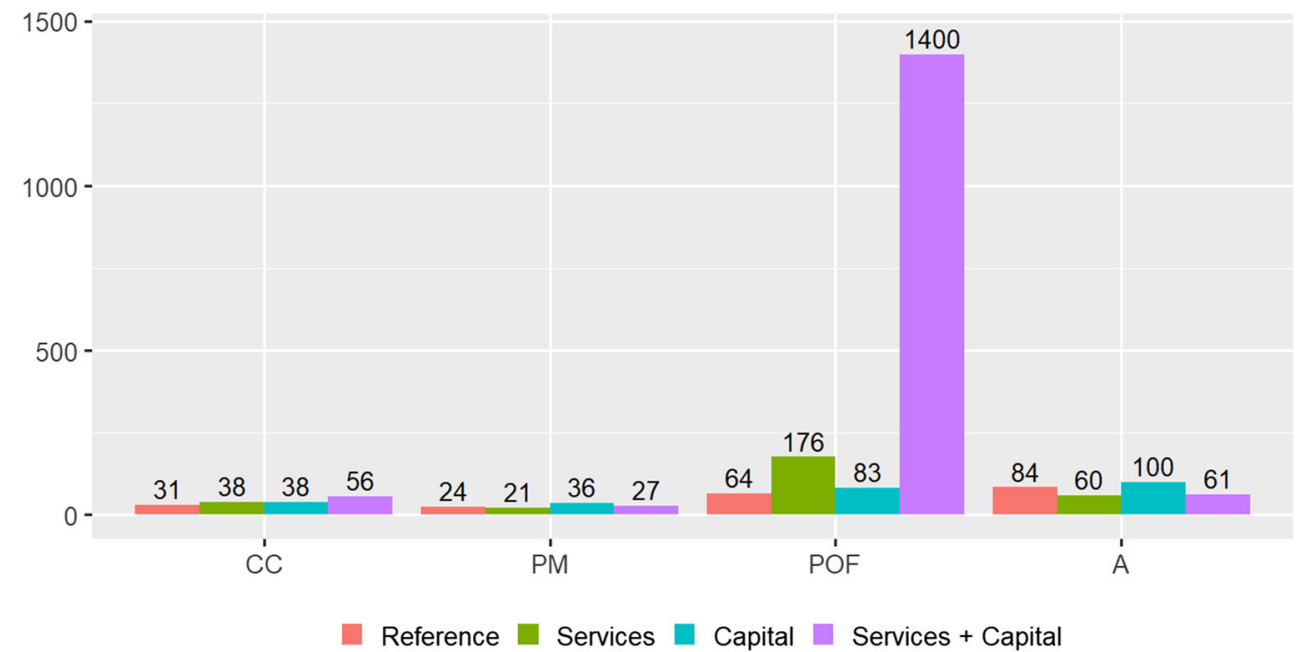


and detail. For instance, Ward et al. (2018b) estimated the impact of missing services in LCA based on a crude analysis of an IOT for a single country. By focusing on a specific LCI system, the method presented here is thus able to account for its intrinsic characteristics, such as geographical boundaries, product detail, and system completeness (Majeau-Bettez et al. 2011). The approach presented here thus offers improvements in terms of representativeness (multiple applications), scope (multiple environmental impacts and simultaneously including both services and capital), and detail (industry and process-specific results), yielding more robust estimates of the role of services and capital in footprint modelling. Despite such novelty, it merits noting that a more complete picture of the role of services and capital in footprint modelling would need to cover other widely used databases, such as other ecoinvent LCI datasets, the U.S. Life Cycle Inventory Database, or input-output databases such as WIOD and Eora. Such potential exercises can apply the same principles proposed in this study, namely using hybrid LCA and growth and productivity accounts to respectively include services and endogenise capital.

In a broader sense, the proposed use of hybrid LCA to improve the representation of both services and their associated capital use contributes to the ongoing discussion about the role of this tool in completing system boundaries in LCA (Gibon and Schaubroeck 2017; Pomponi and Lenzen 2018; Schaubroeck 2019; Schaubroeck and Gibon 2017; Yang 2017a, 2017b; Yang and Heijungs 2019). While it is unquestionable that improving system completeness will theoretically yield more accurate footprint results (Pomponi and Lenzen 2018), it is equally unquestionable that this need not necessarily hold in practice, in this case through hybrid LCA applications. This is because aggregation errors in input-output systems (Yang 2017a) as well as data and methodological issues (Schaubroeck and Gibon 2017) can outweigh the truncation error itself. This study applies a rather pragmatic and simple approach to systematically include missing services, which means that re-calculated footprints from specific unit processes may not be more accurate. In fact, the long tails observed in both Figs. 4 and 5 may highlight a combination of aggregation, data, and methodological issues to be further studied. Indeed, it is unlikely that the inclusion of services in certain processes entails a tenfold increase in their associated footprints (see Fig. 5). Notwithstanding specific cases, hybrid LCA and our specific application can nevertheless be greatly informative to study general patterns. In agreement with Pomponi and Lenzen (2018), it merits noting that the Leontief model is not intended for forecasting purposes and it may show clear limitations in a decision-making context that involves changes. In any case, and similarly to the question of whether hybrid LCA will per se yield superior accuracy, increased sophistication of economic behaviour is not a guarantee of superior predictive ability nor value for impact analysis. In this sense, both completing system boundaries and more realistic economic modelling are both complementary and worthy goals for the advancement of footprint modelling (Schaubroeck 2019).

This study offers first-order estimates of the role of services and capital in various footprint analyses, and it can be further developed in a number of ways. Regarding capital endogenisation, the approach developed by Södersten et al. (2018a, 2018b) and largely applied here can be complemented by considering the intertemporal dynamics of capital stocks, namely the contributions of capital input from different times and regions (Chen et al. 2018). Including capital stock dynamics can be especially valuable in forward-looking applications and when dealing with consequential modelling and model families with sophisticated treatment of markets (Pauliuk et al. 2015). Moreover, CFC "does not describe the physical use of capital goods in production but their estimated loss in value as a result of their use and obsolescence" (Södersten et al. 2018b, 20), and so a more adequate approach could be to use capital services instead (Diewert 2005). Regarding the inclusion of services in LCA, the approach presented here can be improved in various ways. First, service inputs can be better calculated if the cost of value added (e.g. labour costs) is considered in all unit processes, which would help to further ensure that economic balances are not violated. Second, the approach applied here is likely to suffer from double-counting issues that must not be overlooked. For example, the use of some machinery can appear both as a physical input (e.g. in units) in the corresponding LCI processes as well as via services (e.g. leasing and renting) from the IO system. To avoid this issue, a more sophisticated approach could correct these imbalances according to industry-specific knowledge. Last but not least, it merits noting that, by definition, LCI systems suffer from systematic cut-off issues which lead to greatly differing levels of economic completeness between LCI and IO systems (Majeau-Bettez et al. 2011). Therefore, adding service inputs from an IO into an LCI system does not only reflect additional environmental impacts derived from the services themselves, but also from the greater completeness of IO systems. A more consistent, albeit resource-intensive, analysis of the implications of adding services into an LCI system could deal with this issue by levelling the completeness between both systems, for example by completing missing inventories by means of primary data collection and/or hybrid LCA (Crawford et al. 2018). In practical terms, this would likely reduce the relative changes reported in this study, albeit the magnitude of such reduction is unclear.

\section{Conclusions}

This article addresses the implications of endogenising capital in an IO system as well as completing the service inputs in an LCI system in various footprinting applications. The results suggest that omitting both services and capital can lead to 
highly underestimate footprint estimates. The main implication for footprint modellers is that such underestimation can lead to systematic errors and potentially misleading conclusions on environmental hotspots and superiority in comparative analyses, albeit the specific implications depend on the research question and scope of analysis. Indeed, the results vary greatly across types of analysis (e.g. LCA, IOA, comparison between IOA and LCA, and hybrid LCA), impact categories chosen and industries/products studied. These findings have broader implications on two fundamental aspects for footprint modelling: the trade-offs between external and internal ontological consisten$\mathrm{cy}$, and the facilitation of model integration.

First, using an IO system to include services in an LCAbased footprint analysis entails a crucial trade-off between external and internal ontological consistency. On the one hand, external ontological consistency relates to the similitude between the system description in any given footprint model and the observations of the object of study, namely the socioeconomic metabolism (SEM). On the other hand, internal ontological consistency relates to the similitude between systems that are combined in a common analytical framework. In this case, the system completeness of LCA is increased by including service inputs, yet at the expense of internal inconsistencies stemming from ontological discrepancies between IO and LCI systems (e.g. waste flows and life cycle stages). Two possible solutions could be applied to simultaneously minimise both external and internal inconsistencies. A specific solution is to expand the amount of service-related unit processes in the LCI system, which would require extensive data collection. A more generalisable solution is to exploit the potential of integrated hybrid LCA to create a highly interconnected hybrid system. In such a system, the upstream cut-off matrix could be used, for example, to incorporate non-service inputs, such as regionspecific electricity mixes. Simultaneously, the downstream cut-off matrix could be used, for example, to incorporate technology-detailed production inputs and waste flows.

Lastly, the approach presented here shows how footprint models can complement each other towards more comprehensive and consistent SEM descriptions through integrated approaches. Integration is, however, often hampered by differences in data standards and modelling assumptions. In the context of an increased need for model integration, it is essential to develop practical ontologies based on common data and computational structures that help overcome differences in modelling and theoretical traditions, scope, technology detail, etc. Defining clear, complete and consistent ontologies will greatly facilitate overcoming such differences to achieve more effective interdisciplinary research.

Acknowledgements This research is part of the 'Effective environmental policies in Europe in the context of rebound effects' (EFFECT) project (effectprojectblog.wordpress.com), a Marie Skłodowska-Curie Individual Fellowship project (H2020-MSCA-IF-2015, grant agreement no. 702869). I am grateful to Arkaitz Usubiaga, Bo Weidema, and Ivan
Muñoz for comments on an earlier draft, as well as to two anonymous reviewers and Yi Yang for their valuable suggestions.

Open Access This article is distributed under the terms of the Creative Commons Attribution 4.0 International License (http:// creativecommons.org/licenses/by/4.0/), which permits unrestricted use, distribution, and reproduction in any medium, provided you give appropriate credit to the original author(s) and the source, provide a link to the Creative Commons license, and indicate if changes were made.

\section{References}

Ahmad N (2007) The OECD input-output database and supply-use tables in SNA $1993 \mathrm{rev}$ 1. In $O E C D$-NBS workshop on National Accounts, Beijing, China

Chen Z-M, Ohshita S, Lenzen M, Wiedmann T, Jiborn M, Chen B, Lester L, Guan D, Meng J, Xu S, Chen G, Zheng X, Xue JJ, Alsaedi A, Hayat T, Liu Z (2018) Consumption-based greenhouse gas emissions accounting with capital stock change highlights dynamics of fast-developing countries. Nat Commun 9:3581. https://doi.org/10. 1038/s41467-018-05905-y

Crawford RH (2008) Validation of a hybrid life-cycle inventory analysis method. J Environ Manag 88:496-506. https://doi.org/10.1016/J. JENVMAN.2007.03.024

Crawford RH, Bontinck P-A, Stephan A, Wiedmann T, Yu M (2018) Hybrid life cycle inventory methods - a review. J Clean Prod 172: 1273-1288. https://doi.org/10.1016/j.jclepro.2017.10.176

Creutzig F, Popp A, Plevin R, Luderer G, Minx J, Edenhofer O (2012) Reconciling top-down and bottom-up modelling on future bioenergy deployment. Nat Clim Chang 2:320-327. https://doi. org/10.1038/nclimate1416

Diewert WE (2005) Issues in the measurement of capital services, depreciation, asset price changes, and interest rates. In: Measuring capital in the new economy. University of Chicago Press, pp 479-556

EC, FAO, OECD, World Bank, U (2014) System of environmentaleconomic accounting 2012: central framework. doi: ST/ESA/ STAT/Ser.F/109

EC, IMF, OECD, UN and WB (2009) System of National Accounts 2008

ECB (2018) Reference rates. Eur Cent Bank Available at: http://sdw.ecb. europa.eu/browse.do?node=9691296 [Accessed December 17, 2018]

Eurostat (2018) Inflation in the euro area. Available at: https:/ec.europa.eu/ eurostat/statistics-explained/index.php/Inflation_in_the_euro_area

Font Vivanco D, Freire-González J, Kemp R, Van Der Voet E (2014) The remarkable environmental rebound effect of electric cars: a microeconomic approach. Environ Sci Technol 48:12063-12072. https:// doi.org/10.1021/es5038063

Font Vivanco D, Tukker A, Kemp R (2016) Do methodological choices in environmental modeling bias rebound effects? A case study on electric cars. Environ Sci Technol 50:11366-11376. https://doi.org/ 10.1021/acs.est.6b01871

Font Vivanco D, van der Voet E (2014) The rebound effect through industrial ecology's eyes: a review of LCA-based studies. Int J Life Cycle Assess 19:1933-1947. https://doi.org/10.1007/s11367014-0802-6

Francois J, McDonald B (1996) Liberalization and capital accumulation in the GTAP model. GTAP Tech Pap 8

Freire-González J (2011) Methods to empirically estimate direct and indirect rebound effect of energy-saving technological changes in households. Ecol Model 223:32-40. https://doi.org/10.1016/j. ecolmodel.2011.09.001

Gibon T, Schaubroeck T (2017) Lifting the fog on characteristics and limitations of hybrid LCA - a reply to "Does hybrid LCA with a 
complete system boundary yield adequate results for product promotion?" by Yi Yang. Int J Life Cycle Assess 22(3):456-406. https://doi.org/10.1007/s11367-016-1256-9 Int J Life Cycle Assess 22:1005-1008. doi:10.1007/s11367-017-1291-1

Huysman S, Schaubroeck T, Goralczyk M, Schmidt J, Dewulf J (2016) Quantifying the environmental impacts of a European citizen through a macro-economic approach, a focus on climate change and resource consumption. J Clean Prod 124:217-225. https://doi. org/10.1016/J.JCLEPRO.2016.02.098

Jäger K (2016) EU KLEMS Growth and Productivity Accounts 2017 Release, Statistical Module. The Conference Board Available at: http://www.euklems.net/TCB/2017/Metholology_EU KLEMS_ 2017.pdf

Joshi S (1999) Product environmental life-cycle assessment using inputoutput techniques. J Ind Ecol 3:95-120. https://doi.org/10.1162/ 108819899569449

Lenzen M (2000) Errors in conventional and input-output-based lifecycle inventories. J Ind Ecol 4:127-148. https://doi.org/10.1162/ 10881980052541981

Lenzen M, Treloar GJ (2004) Endogenising capital. J Appl Input-Output Anal 10:1-11

Majeau-Bettez G, Dandres T, Pauliuk S, Wood R, Hertwich E, Samson R, Strømman AH (2018) Choice of allocations and constructs for attributional or consequential life cycle assessment and input-output analysis. J Ind Ecol 22:656-670. https://doi.org/10.1111/jiec.12604

Majeau-Bettez G, Strømman AH, Hertwich EG (2011) Evaluation of process- and input-output-based life cycle inventory data with regard to truncation and aggregation issues. Environ Sci Technol 45: 10170-10177. https://doi.org/10.1021/es201308x

Miller RE, Blair PD (2009) Input-output analysis: foundations and extensions. Cambridge University Press, Cambridge, UK

Minx JC, Wiedmann T, Wood R, Peters GP, Lenzen M, Owen A, Scott K, Barrett J, Hubacek K, Baiocchi G, Paul A, Dawkins E, Briggs J, Guan D, Suh S, Ackerman F (2009) Input-output analysis and carbon footprinting: an overview of applications. Econ Syst Res 21: 187-216. https://doi.org/10.1080/09535310903541298

Myers RJ, Fishman T, Reck BK, Graedel TE (2019) Unified materials information system (UMIS): an integrated material stocks and flows data structure. J Ind Ecol 23:222-240

Nansai K, Kagawa S, Suh S, Fujii M, Inaba R, Hashimoto S (2009) Material and energy dependence of services and its implications for climate change. Environ Sci Technol 43:4241-4246. https:// doi.org/10.1021/es 8025775

Palmer K, Tate JE, Wadud Z, Nellthorp J (2018) Total cost of ownership and market share for hybrid and electric vehicles in the UK, US and Japan. Appl Energy 209:108-119. https://doi.org/10.1016/J. APENERGY.2017.10.089

Pauliuk S, Majeau-Bettez G, Müller DB, Hertwich EG (2016) Toward a practical ontology for socioeconomic metabolism. J Ind Ecol 20: 1260-1272. https://doi.org/10.1111/jiec.12386

Pauliuk S, Wood R, Hertwich EG (2015) Dynamic models of fixed capital stocks and their application in industrial ecology. J Ind Ecol 19: 104-116. https://doi.org/10.1111/jiec.12149

Pomponi F, Lenzen M (2018) Hybrid life cycle assessment (LCA) will likely yield more accurate results than process-based LCA. J Clean Prod 176:210-215. https://doi.org/10.1016/J.JCLEPRO.2017.12.119

Saunders HD (2000) A view from the macro side: rebound, backfire, and Khazzoom-Brookes. Energy Policy 28:439-449 Available at: http:// www.sciencedirect.com/science/article/pii/S0301421500000240

Schaubroeck T (2019) Both completing system boundaries and realistic modeling of the economy are of interest for life cycle assessment- - a reply to "Moving from completing system boundaries to more realistic modeling of the economy in life cycle assessment" by Yang and Heijungs (2018). Int J Life Cycle Assess 24:219-222. https://doi. org/10.1007/s11367-018-1546-5
Schaubroeck T, Gibon T (2017) Outlining reasons to apply hybrid LCA - a reply to "Rethinking system boundary in LCA" by Yi Yang (2017). Int J Life Cycle Assess 22:1012-1013. https://doi. org/10.1007/s11367-017-1311-1

Södersten C-J, Wood R, Hertwich EG (2018a) Environmental impacts of capital formation. J Ind Ecol 22:55-67. https://doi.org/10.1111/jiec. 12532

Södersten C-J, Wood R, Hertwich EG (2018b) Endogenizing capital in MRIO models: the implications for consumption-based accounting. Environ Sci Technol 52:13250-13259. https://doi.org/10.1021/acs. est. 8 b02791

Stadler K, Wood R, Bulavskaya T, Södersten C-J, Simas M, Schmidt S, Usubiaga A, Acosta-Fernández J, Kuenen J, Bruckner M, Giljum S, Lutter S, Merciai S, Schmidt JH, Theurl MC, Plutzar C, Kastner T, Eisenmenger N, Erb KH, de Koning A, Tukker A (2018) EXIOBASE 3: developing a time series of detailed environmentally extended multi-regional input-output tables. J Ind Ecol 20:1325013259. https://doi.org/10.1111/jiec. 12715

Suh S (2004) Functions, commodities and environmental impacts in an ecological-economic model. Ecol Econ 48:451-467. https://doi. org/10.1016/j.ecolecon.2003.10.013

Suh S (2006) Are services better for climate change? Environ Sci Technol 40:6555-6560. https://doi.org/10.1021/es0609351

Suh S, Lenzen M, Treloar GJ, Hondo H, Horvath A, Huppes G, Jolliet O, Klann U, Krewitt W, Moriguchi Y, Munksgaard J, Norris G (2004) System boundary selection in life-cycle inventories using hybrid approaches. Environ Sci Technol 38:657-664. https://doi.org/10. $1021 / \mathrm{es} 0263745$

Teh SH, Wiedmann T, Castel A, de Burgh J (2017) Hybrid life cycle assessment of greenhouse gas emissions from cement, concrete and geopolymer concrete in Australia. J Clean Prod 152:312-320. https://doi.org/10.1016/J.JCLEPRO.2017.03.122

Tillman A-M, Ekvall T, Baumann H, Rydberg T (1994) Choice of system boundaries in life cycle assessment. J Clean Prod 2:21-29. https:// doi.org/10.1016/0959-6526(94)90021-3

Ward H, Wenz L, Steckel JC, Minx JC (2018a) Truncation error estimates in process life cycle assessment using input-output analysis. J Ind Ecol 22:1080-1091. https://doi.org/10.1111/jiec.12655

Ward H, Wenz L, Steckel JC, Minx JC (2018b) Truncation error estimates in process life cycle assessment using input-output analysis. J Ind Ecol 22:1080-1091. https://doi.org/10.1111/jiec.12655

Weidema B, Bauer C, Hischier R, Mutel C, Nemecek T, Reinhard J et al (2013) Overview and methodology: data quality guideline for the ecoinvent database version 3. Available at: http://vbn.aau.dk/ws/ files/176769045/Overview_and_methodology.pdf

Wernet G, Bauer C, Steubing B, Reinhard J, Moreno-Ruiz E, Weidema B (2016) The ecoinvent database version 3 (part I): overview and methodology. Int J Life Cycle Assess 21:1218-1230. https://doi. org/10.1007/s11367-016-1087-8

Yang Y (2017a) Does hybrid LCA with a complete system boundary yield adequate results for product promotion? Int J Life Cycle Assess 22:456-460. https://doi.org/10.1007/s11367-016-1256-9

Yang Y (2017b) Rethinking system boundary in LCA — reply to "Lifting the fog on the characteristics and limitations of hybrid LCA" by Thomas Gibon and Thomas Schaubroeck (2017). Int J Life Cycle Assess 22:1009-1011. https://doi.org/10.1007/s11367-017-1295-x

Yang Y, Heijungs R (2019) Moving from completing system boundaries to more realistic modeling of the economy in life cycle assessment. Int J Life Cycle Assess 24:211-218. https://doi.org/10.1007/s11367018-1532-y

Publisher's note Springer Nature remains neutral with regard to jurisdictional claims in published maps and institutional affiliations. 